\title{
Association of Atorvastatin with Increased Growth and Quality of Immature Mouse Oocytes In-Vitro
}

Morteza Sadeghi ${ }^{1}$, Fatemeh Sabbaghziarani ${ }^{2}$, Pourya Soleimani ${ }^{3}$, Mohammad Reza Ashtarimajelan ${ }^{4}$, Fariba Zafari $^{5}$

1. Assistant Professor, Human Genetics Research Center, Baqiyatallah University of Medical Sciences, Tehran, Iran. ORCID ID: 0000-0003-3453-0010

2. Assistant Professor, Cellular and Molecular Research Center, Research Institute for Prevention of Non-Communicable Diseases, Qazvin University of Medical Sciences, Qazvin, Iran. ORCID ID: 0000-0002-5167-3569

3. Bsc Student, Student Research Committee, Faculty of Medicine, Qazvin University of Medical Sciences, Qazvin, Iran. ORCID ID: 0000-0002-5937-6390

4. Msc, Student Research Committee, Faculty of Medicine, Qazvin University of Medical Sciences, Qazvin, Iran. ORCID ID: 0000-0002-3186-6486

5. Assistant Professor, Cellular and Molecular Research Center, Research Institute for Prevention of Non-Communicable Diseases, Qazvin University of Medical Sciences, Qazvin, Iran., (Corresponding author), Tel: +98-28-33336001, Email: f.zafari@qums.ac.ir, ORCID ID: 0000-0001-6673-278X

\begin{abstract}
Background and Aim: Atorvastatin is one of the medicines used for the treatment of high blood cholesterol which recently has been shown to have antioxidant effects in the cell. The aim of this study was to evaluate the effect of atorvastatin on the growth and quality of immature mouse oocytes in vitro.
\end{abstract}

Materials and Methods: 400 oocytes were prepared from ovaries of 40 NMRI mice and divided into two groups of control (culture medium) and atorvastatin (culture medium $+2 \mu \mathrm{M}$ atorvastatin). Then oocyte qualitative parameters including zona pellucida thickness (ZP), Perivitelline space size (PVS) and oocyte diameter (OD) were determined using invert microscope and image-J software.

Results: Quantitative parameters of zona pellucida thickness and oocyte diameter were increased in the atorvastatin group compared to those in the control group. In the evaluation of oocytes quality, the number of oocytes exhibiting +1 score in the atorvastatin and control groups were $(70 \%)$ and $(55.4 \%)$ respectively, which showed a significant difference between the two groups $(\mathrm{P} \leq 0.05)$. The numbers of polar bodies exhibiting +1 score in the atorvastatin and control groups were $(36.18 \%)$ and $(18.5 \%)$ respectively $(\mathrm{P} \leq 0.05)$.

Conclusion: Use of atorvastatin had a significant effect on the growth and final quality of the immature oocytes in vitro and it can possibly be used to increase the efficiency of in vitro fertilization in the future.

Keywords: Atorvastatin, Oocyte, Maturation, Infertility

Received: Dec 10, $2019 \quad$ Accepted: Mar 1, 2021

How to cite the article: Morteza Sadeghi, Fatemeh Sabbaghziarani, Pourya Soleimani, Mohammad Reza Ashtarimajelan, Fariba Zafari. Association of Atorvastatin with Increased Growth and Quality of Immature Mouse Oocytes in Vitro.वُट́SJKU 2021;26(4):30-37.

Copyright (C) 2018 the Author (s). Published by Kurdistan University of Medical Sciences. This is an open access article distributed under the terms of the Creative Commons Attribution-Non Commercial License 4.0 (CCBYNC), where it is permissible to download, share, remix, transform, and buildup the work provided it is properly cited. The work cannot be used commercially without permission from the journal 


\section{ارتباط آتورواستاتين با افزايش رشد و كيفيت تخمكهاى نارس موش \\ In-Vitro در محيط}

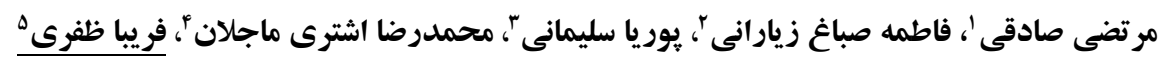

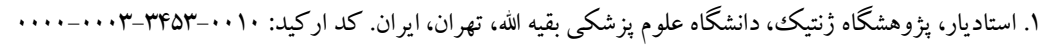

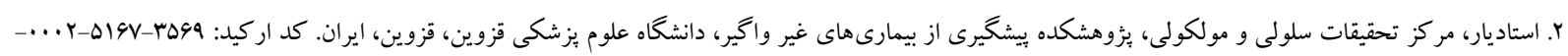

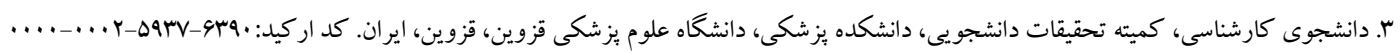

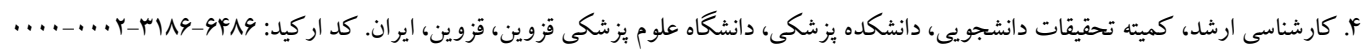

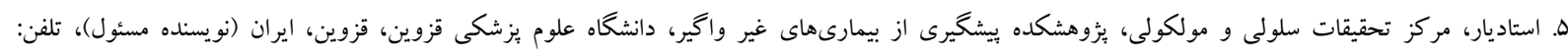

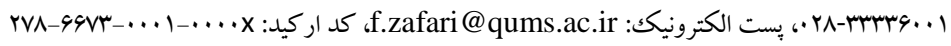

جكکنه

زمينه و هدف: آتورواستاتين از داروهاى مورد استفاده در درمان كلسترول بالاى خون است كه به تازگى مشخص شده داراى

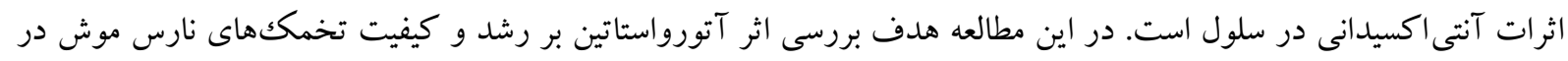
محيط in vitro است.

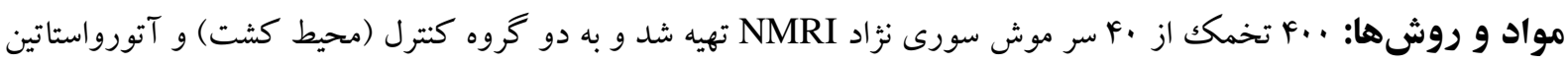

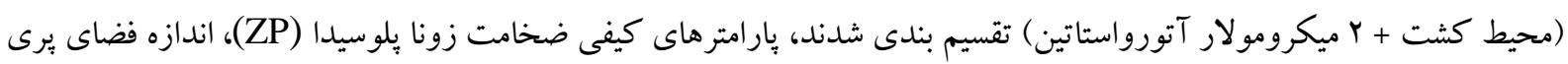

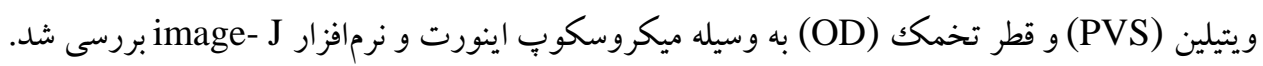

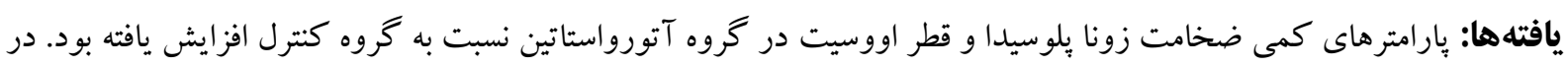

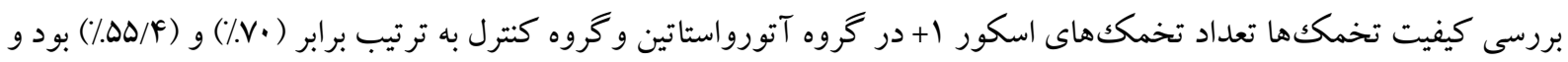

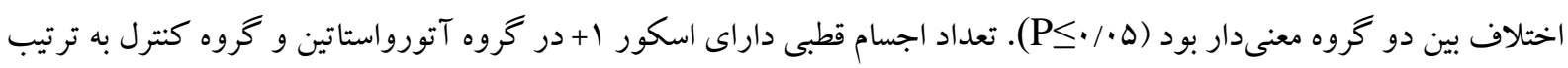

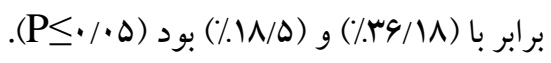
نتيجه كيرى: استفاه از آتورواستاتين تاثير قابل توجهى در رشد و كيفيت نهايى تخمككهاى نارس در محيط آزمايشگاهى دارد و و

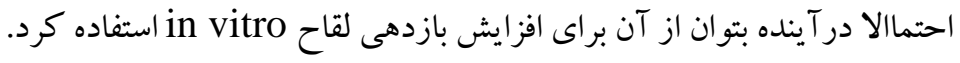
وازهاى كليدى: آتورواستاتين، تخمكى، بلوغ، نازايى

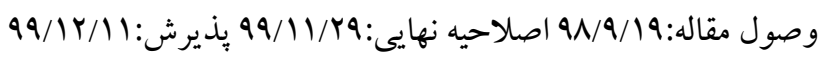


آتورواستاتين با دوز كم عوارض جانبى در بارورى و توليد

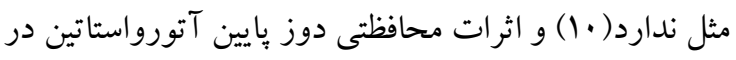

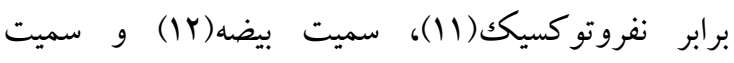

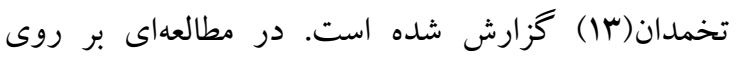

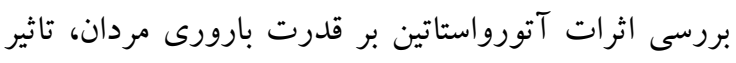
قابل توجه آتورواستاتين در افزايش تعداد اسبرم و ميزان

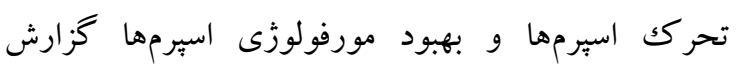
شد(f) (1). همجنين گزارش شده است كه آتورواستاتين باعث افزايش بيانVEGF در تخمدانها مىشود و از اين طريق

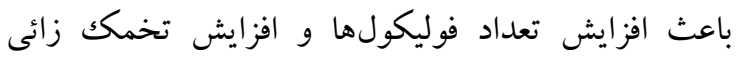
مىشود( له ) و آتورواستاتين باعث ترميم آسيبهاى ناشى از

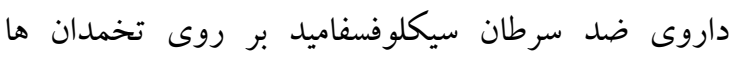
مىشود و به باز گشت تخمدان ها به حالت فعال كمكك مى سيكل

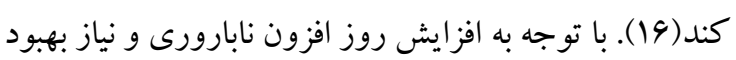

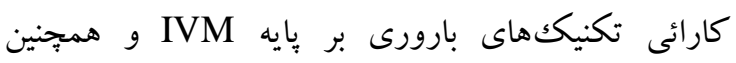

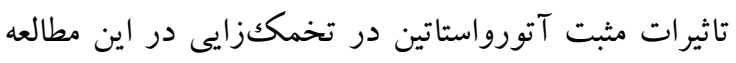

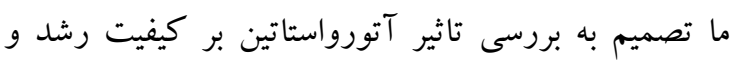
بلوغ تخمككهاى نابالغ موش سورى در محيط آزمايشكاه كرفتيم. - مكن.

\section{مواد و روشها}

تهيه حيوانات و جمع آورى تخمكك:

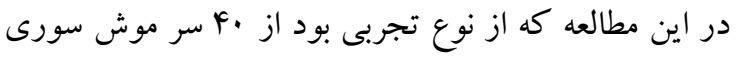

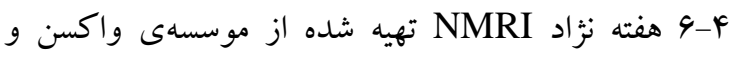
سرمسازى رازى استفاده شد، به منظور تطابق با شرايط محيطى جديد موشها به مدت يكك هفته در حيوان خانه

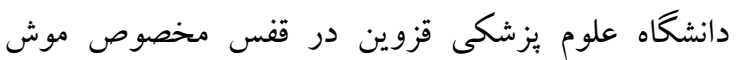

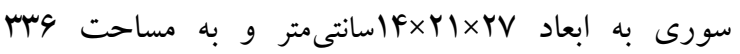

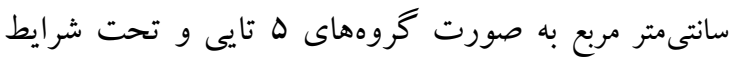

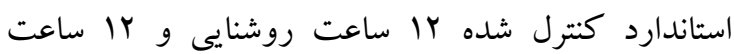

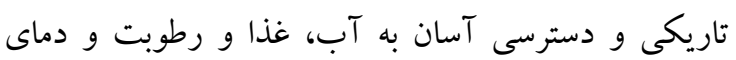

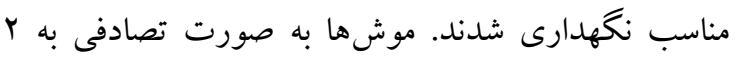

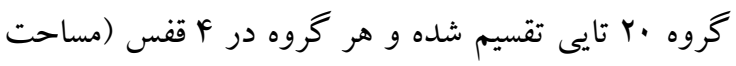

مقدمه نازايى يكى از موضوعات سلامت عمومى و رو به گسترش در جهان است كه با سلامت عمومى و روانى زوجين در

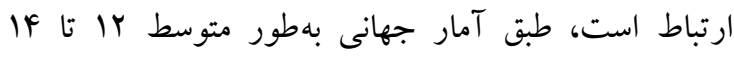
درصد از زوجها نابارور هستند(1). In vitro IVM ) يكى از تكنيككهاى درمان نازايى با استفاده

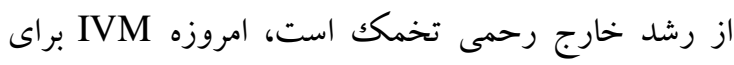

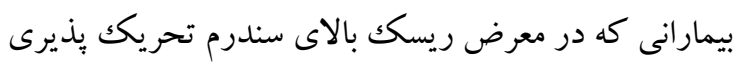

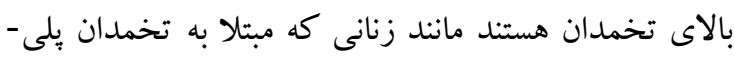
كيستيك هستند يا بيمارانى كه نياز به آغاز درمانهاى

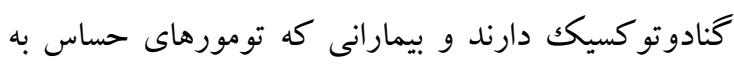
هورمون دارند كاربرد حياتى دارد (Y). از مهم ترونين

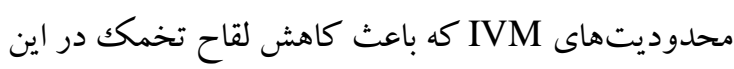
تكنيك مى شود تفاوتهاى محيط آزمايشگاه با محيط داخل

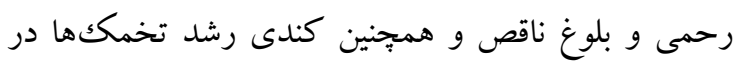

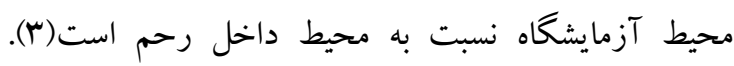
راديكالهاى آزاد (ROS)، يكى از مهم ترين عواملى هستند

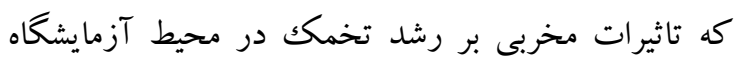
دارند و باعث القاء آيويتوز و مر كى تخمككها مىشود (F).

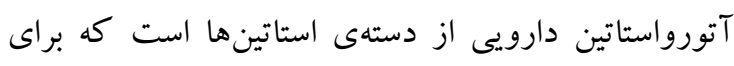
كاهش ميزان كلسترول خون تجويز مىشود(ه). مطالعات نشان مى دهد آتورواستاتين از طريق مهار آنزيم اثرات راديكالهاى ازاد و استرسهاى اكسيداتيو مقابله مى -

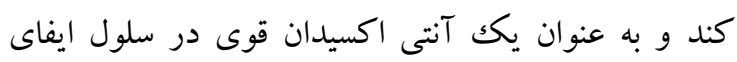

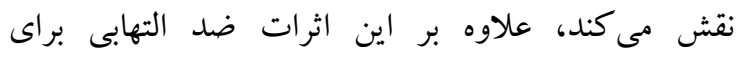

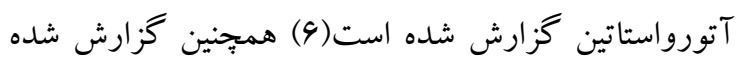

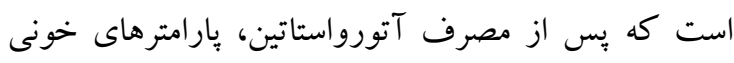

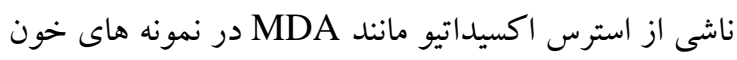
بيماران به طور معنى دارى كاهش مي يابد به علاوه كلسترول

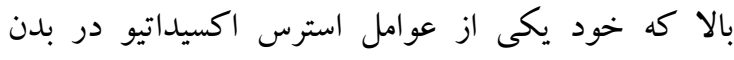
محسوب مىشود توسط آتورواستاتين كاهش مىيابد(V).

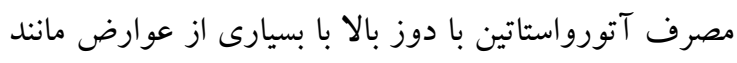

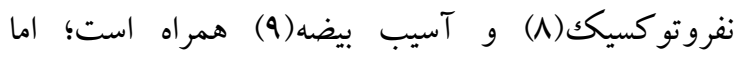


اينورت تخمككهايى كه تقسيم ميوز اول را طى كرده و داراى جسم قطبى اول بودند شمارش و عكسبردارى شدند. تخمككها در گروهها بر اساس جدول اسكوربندى (اندازه قطر تخمك و مشخصات جسم قطبى، الكوى سيتويلاسمى،

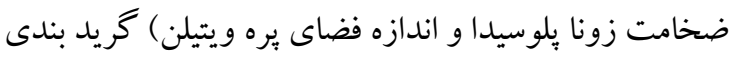

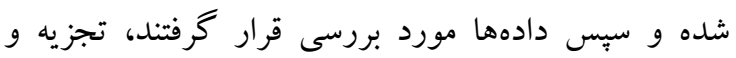

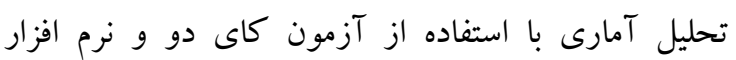
SPSS اندازه گيرى و اسكوربندى تخمك ها:

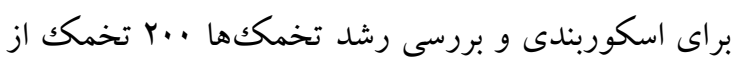

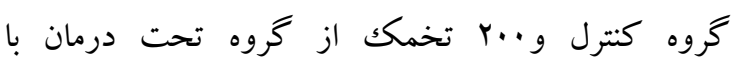

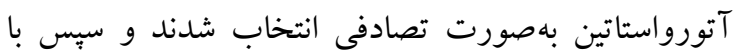

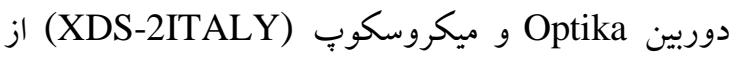
تخمككها عكسبردارى شد و تصاوير حاصل به كمكك نرمافزار Image j بررسى شد. در اسكوربندى تخمكهها

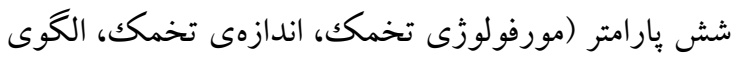
سيتويلاسم، فضاى پيرى وتلين، زونا پِلاسيدا (ZP) و مورفولوزى جسم قطبى مورد بررسى قرار گرفت. براى هر

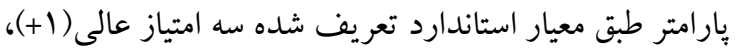

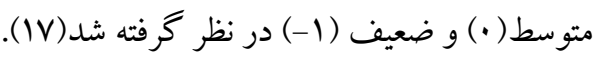
$-1$
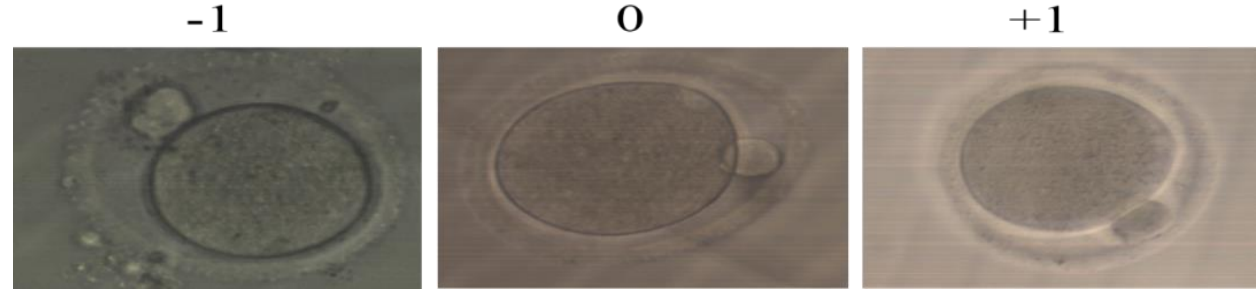

شكل ا. تصوير سه تخمك با درجات مختلف كيفيت. كيفيت عالى (1+)، كيفيت متوسط (.) و كيفيت بد (1-)، در تخمك ا+موروفوفولوزى و بلوغ كامل تر است و جسم قطبى به خوبى تشكيل شده است. 


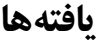

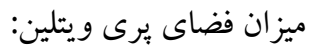

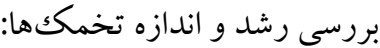
ميانگين فضاى برى ويتلين (PVS) در گروه آتورواستاتين و در بررسى رشد و كيفيت تخمككها پارامترهاى ضخامت

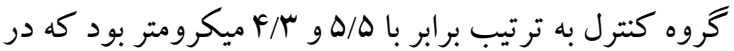
زونا بِلوسيدا (ZP)، قطر تخمك، فضاى برى ويتلين (PVS)،

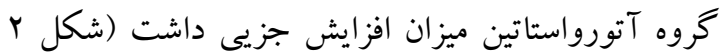

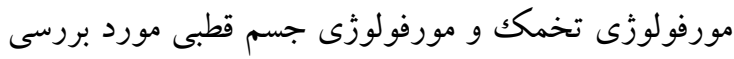

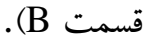
قرار گرفت كه نتايج بهصورت زير بود:

قطر تخمك

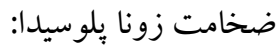
ميانخين قطر تخمككهاى كشت شده در گروه كنترل و ميانگين اندازهى زونا بلوسيدا (ZP) در گروه كنترل و گروها

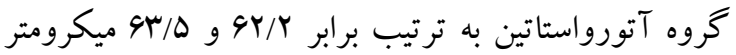

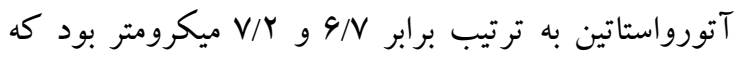

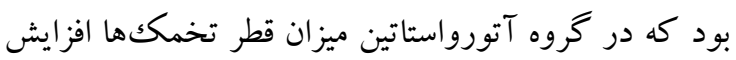

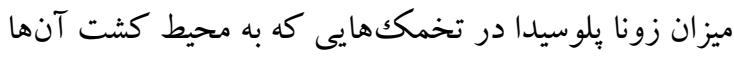

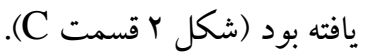

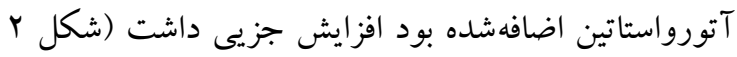

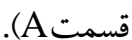
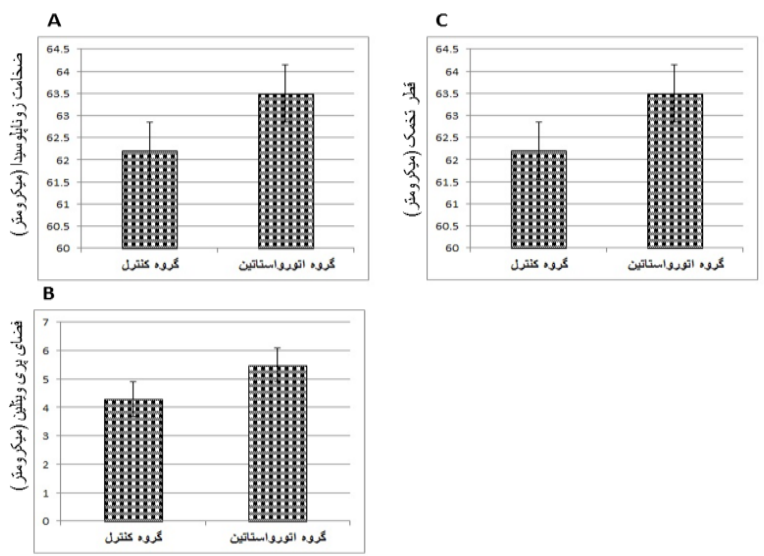

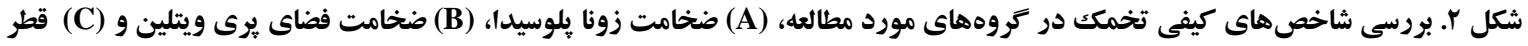

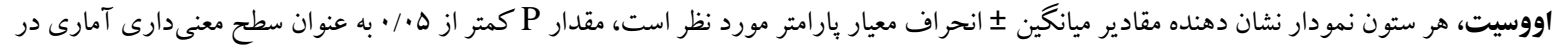
نظر كرفته شده است.

مورفولوزى جسم قطبى (PB) در كروههاى آتورواستاتين

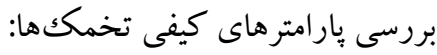

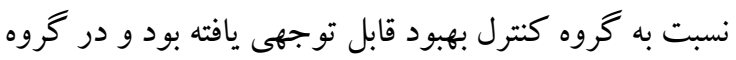

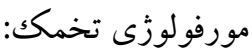

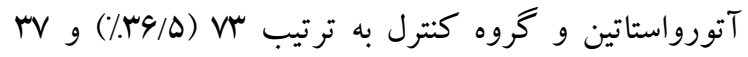
مورفولوزى تخمككهايى كه در محيط كشت حاوى تحون

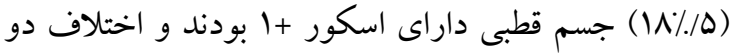
آتورواستاتين كشت داده شده بودند به طور معنى دارى بهبود

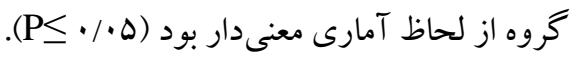

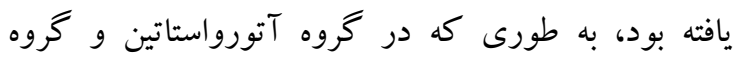

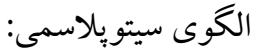
در بررسى بِارامتر الكوى سيتوبلاسمى در دو گروهي مورد

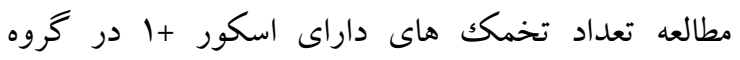

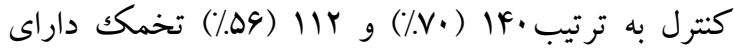

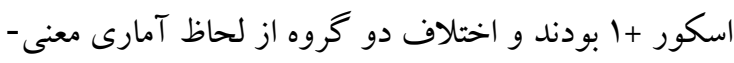

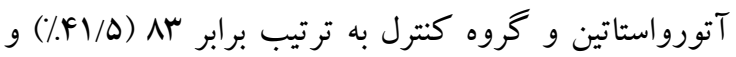
دار بود (P) (P

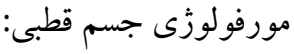




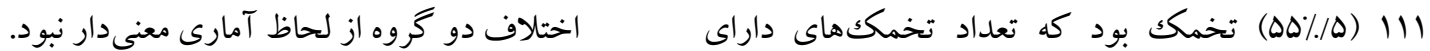
اسكور +1 در كروه آتورواستاتين افزايش داشت؛ ولى بهد تهدي جدول 1. بررسى شاخصهاى كيفى مورفولوزى تخمكك و مرفولوزى جسم قطبى و الكوى سيتويلاسمى در گروههاى مورد مطالعه. مقدار P كمتر از هـاء.

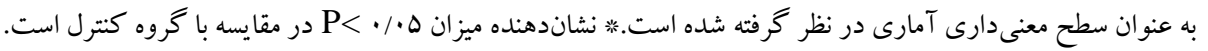

\begin{tabular}{|c|c|c|}
\hline كروه آتورواستاتين & كروه كنترل & شاخص \\
\hline تعداد (درصد) & تعداد (درصد) & مورفولوزى تخمك \\
\hline$(1 \cdot) r \cdot$ & $(r \cdot) r$. & -1 \\
\hline$(Y \cdot) F$. & $(Y F) F A$ & . \\
\hline \multirow[t]{2}{*}{$*(v \cdot) \backslash f}$. & 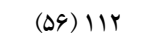 & +1 \\
\hline & & مو رفولوزى جسم قطبى \\
\hline$(r / \Delta / \Delta) 99$ & $(q F / \Delta) \wedge q$ & -1 \\
\hline$(r q) \Delta \wedge$ & $(r V) V F$ & · \\
\hline \multirow[t]{2}{*}{$*(r g / \Delta) v r$} & $(1 N / Q) r V$ & +1 \\
\hline & & الكوى سيتويلاسمى \\
\hline$(r Y / \Delta) F r$ & $(r / / \Delta) \& r$ & -1 \\
\hline (YT) 49 & $(r V) V F$ & . \\
\hline$(\Delta \Delta / \Delta) \| 11$ & $(F \mid / \Delta) \wedge \mu$ & +1 \\
\hline
\end{tabular}

كه دوزهاى يائين آتورواستاتين داراى اثرات انتى اكسيدانى و ضدالتهابى قوى است(19) همجِنين مشخص شده است كه دوزهاى بائين آتورواستاتين از طريق كاهش التهاب باعث درمان بافت هاى آسيب ديده تخمدانها مىشود و از اين طريق به ايجاد تخمككهاى سالمتر و بلوغ بهتر تخمككها

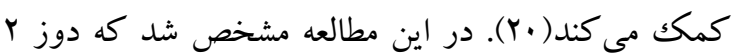
ميكرو موولار آتورواستاتين در محيط كشت باعث رشد بهتر تخمككها و افزايش معنىدار بارامترهاى كيفى تخمك مىشود كه اين تاثير مىتواند ناشى از حذف رادئ داديكالهاى آزاد (ROS) محيط توسط آتورواستاتين باشد. -Pons) Rejraji

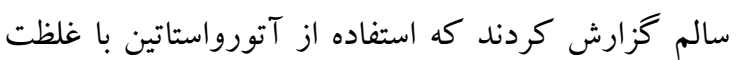
•ا ميلى گرم به مدت ه ماه باعث افزايش كيفيت و ميزان توليد اسبرم در انسان مىشود كه اين اثر مىتواند ناشى از

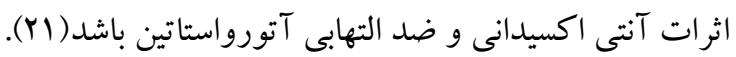

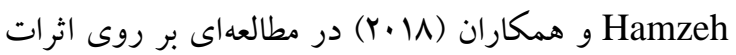

در اين مطالعه ما به بررس اثرات آتورواستاتين در كيفيت و رشد تخمككهاى موش در محيط آزمايشگاهى يرداختيم طبق يافته هاى اين مطالعه تيمار تخمككهاى اوليه موش با لو غلظت r ميكرومولار آتورواستاتين سبب افزايش رشد و ائس اندازه كلى تخمككها و همجنين بهبود پِارامترهاى كيفى تخمك مىشود. كيفيت تخمك در محيط آزمايشاهى از مهمترين فاكتورهايى است كه به طور مستقيم با كارايى لقاح خارج رحمى (IVF) در ارتباط است و به عوامل

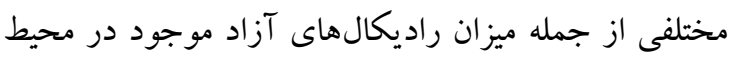

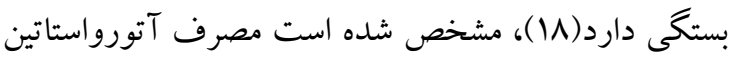
با دوز بالا با عوارضى مانند آسيبهاى بيضه و كليه(ه)؛ اما مصرف آتورواستاتين با دوز كم عوارض جانبى در بارورى ماند و توليد مثل ندارد(·(). استفاده از آتورواستاتين در موش باعث كاهش راديكالهاى آزاد و در نتيجه باعث افزايش زنده ماندن سلولها در موش مىشود و مشخص شده است 


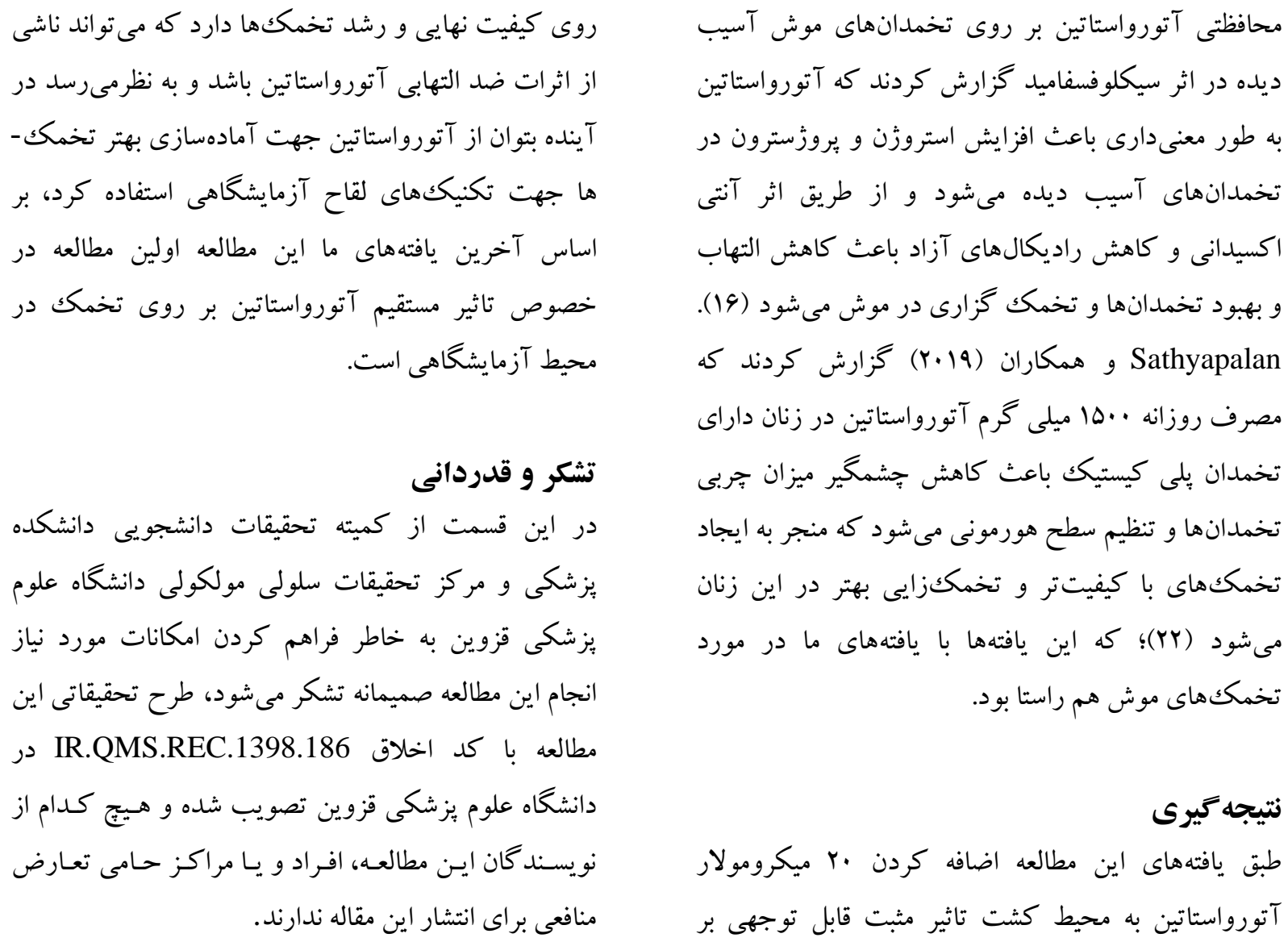

1. Cates W, Farley TM, Rowe PJ. Worldwide patterns of infertility: is Africa different?. The Lancet. 1985; 14;326(8455):596-8.

2. Mather JP. Making Informed Choices: Medium, Serum, and Serum-Free Medium How to Choose the Appropriate Medium and Culture System for the Model You Wish to Create. Method Cell Biol. 1998; 31;57:19-30.

3. Yalçınkaya E, Çalışkan E, Budak Ö. In vitro maturation may prevent the cancellation of in vitro fertilization cycles in poor responder patients: A case report. J Turk Ger Gynecol Assoc. 2013;14(4):235.

4. Ríos GL, Buschiazzo J, Mucci NC, Kaiser GG, Cesari A, Alberio RH. Combined epidermal growth factor and hyaluronic acid supplementation of in vitro maturation medium and its impact on bovine oocyte proteome and competence. Theriogenology. 2015;83(5):87480 .

5. Forst T, Wilhelm B, Pfützner A, Fuchs W, Lehmann U, Schaper F, et al. Investigation of the vascular and pleiotropic effects of atorvastatin and pioglitazone in a population at high cardiovascular risk. Diab Vasc Dis Res. 2008;5(4):298-303.

6. Violi F, Cangemi R, Calvieri C. Pneumonia, thrombosis and vascular disease. J Thromb Haemost . 2014; 1;12(9):1391-400.

7. ÇİFTÇİ GA, Ertorun I, Akalin A, ALATAŞ İÖ, Musmul A. The effects of atorvastatin on antioxidant/antiinflammatory properties of HDLs in hypercholesterolemics. Turk J Med Sci . $2015 ; 45(2): 345-51$ 
8. Nasri H, Hasanpour Z, Nematbakhsh M, Ahmadi A, Rafieian-Kopaei M. The effect of the various doses of atorvastatin on renal tubular cells; an experimental study. J Nephropathol. 2016; 5: 111-115.

9. Klinefelter GR, Laskey JW, Amann RP. Statin drugs markedly inhibit testosterone production by rat Leydig cells in vitro: Implications for men. Reprod Toxicol. 2014; 45: 5258.

10. Dostal LA, Whitfield LR, Anderson JA. Fertility and general reproduction studies in rats with the HMG-CoA reductase inhibitor, atorvastatin. Fundam Appl Toxicol. 1996; 32: 285292.

11. Talebpour Amiri F, Hamzeh M, Naeim RA, Ghasemi A, Hosseinimehr SJ. Radioprotective effect of atorvastatin against ionizing radiation-induced nephrotoxicity in mice. Int J Radiat Biol. 2018; 94: 106-113.

12. Naeimi RA, Talebpour Amiri F, Khalatbary AR, Ghasemi A, Zargari M, Ghesemi M, et al. Atorvastatin mitigates testicular injuries induced by ionizing radiation in mice. Reprod Toxicol. 2017; 72: 115-121.

13. Parlakgumus HA, Aka Bolat F, Bulgan Kilicdag E, Simsek E, Parlakgumus A. Atorvastatin for ovarian torsion: effects on follicle counts, AMH, and VEGF expression. Eur J Obstet Gynecol Reprod Biol. 2014; 175: 186-190.

14. Dostal LA, Juneau P, Rothwell CE. Repeated analysis of semen parameters in beagle dogs during a 2-year study with the HMG-CoA reductase inhibitor, atorvastatin. Toxicological Sciences. 2001; 1;61(1):128-34.

15. Parlakgumus A, Aka Bolat F, Kilicdag EB, Simsek E. Atorvastatin for ovarian torsion: effects on follicle counts, AMH, and VEGF expression H. Eur J Obstet Gynecol. 2014;175:186-190

16. Hamzeh M, Hosseinimehr SJ, Mohammadi HR, Yaghubi Beklar S, Dashti A, Talebpour Amiri F. Atorvastatin attenuates the ovarian damage induced by cyclophosphamide in rat: An experimental study. Int J Reprod BioMed. 2018;16(5):323-334.

17. Lazzaroni-Tealdi E, Barad DH, Albertini DF, Yu Y, Kushnir VA, Russell H, et al. Emanuela Lazzaroni-Tealdi, David H. Barad, Oocyte Scoring Enhances Embryo-Scoring in Predicting Pregnancy Chances with IVF Where It Counts Most. PLoS One. 2015; 2;10(12).

18. Hatırnaz S, Ata B, Hatırnaz ES, Dahan MH, Tannus S, Tan J, Lin Tan S. Oocyte in vitro maturation: A sytematic review. Turk J Obstet Gynecol. 2018;15:112-25.

19. Crevar-Sakac M, Vujić Z, Kotur-Stevuljević J, Ivanisević J, Jelić-Ivanović Z, Milenković $\mathrm{M}$, et al. Effects of atorvastatin and artichoke leaf tincture on oxidative stress in hypercholesterolemic rats. Vojnosanit Pregl. 2016; 73: 178-187.

20. Parlakgumus HA, Aka Bolat F, Bulgan Kilicdag E, Simsek E, Parlakgumus A. Atorvastatin for ovarian torsion: effects on follicle counts, AMH, and VEGF expression. Eur J Obstet Gynecol Reprod Biol. 2014; 175: 186-190.

21. Pons-RejrajiH, Brugnon F, Sion B, Maqdasy S, Gouby G, Pereira B, et al. Evaluation of atorvastatin efficacy and toxicity on spermatozoa, accessory glands and gonadal hormones of healthy men: a pilot prospective clinical trial. Reprod Biol Endocrinol. 2014 12:65.

22. Sathyapalan T, Hobkirk JP, Javed Z, Carroll S, Coady A-M, Pemberton P, et al. The Effect of Atorvastatin (and Subsequent Metformin) on Adipose Tissue AcylationStimulatory-Protein Concentration and Inflammatory Biomarkers in Overweight/Obese Women With Polycystic Ovary Syndrome. Front. Endocrinol. 2019; 25;10:394. 